\title{
Cataract service redesign in the post-COVID-19 era
}

\author{
Pei-Fen Lin $\mathbb{C D}^{1}{ }^{1}$ Hasan Naveed ${ }^{2,3}$ Maria Eleftheriadou, ${ }^{1}$ Robert Purbrick, ${ }^{2}$ \\ Mehran Zarei Ghanavati, ${ }^{4}$ Christopher Liu ${ }^{5}$
}

${ }^{1}$ Moorfields Eye Hospital NHS Foundation Trust, London, UK ${ }^{2}$ Sussex Eye Hospital, Brighton and Sussex University Hospitals NHS Trust, Brighton, UK ${ }^{3}$ Brighton and Sussex Medical School, Brighton, UK

${ }^{4}$ Educational Department, Farabi Eye Hospital, Tehran, Iran, Islamic Republic of

${ }^{5}$ Sussex Eye Hospital, Brighton, Brighton, UK

\section{Correspondence to} Pei-Fen Lin, Moorfields Eye Centre at Croydon University Hospital, Moorfields NHS Foundation Trust, London, UK; p.lin@nhs.net

Received 13 May 2020 Revised 18 June 2020 Accepted 27 June 2020 Published Online First 23 July 2020
Check for updates

(C) Author(s) (or their employer(s)) 2021. No commercial re-use. See rights and permissions. Published by BMJ.

To cite: Lin P-F, Naveed $\mathrm{H}_{\text {, }}$ Eleftheriadou $\mathrm{M}$, et al. Br J Ophthalmol 2021:105:745-750.
ABSTRACT COVID-19 pandemic of 2020 has impacted all aspects of clinical practice in the UK. Cataract services suffered severe disruption due to necessary measures taken to reduce elective surgery in order to release capacity to support intensive care requirements. Faced with a potential $50 \%$ increase in cataract surgery workload per week in the post-COVID-19 world, eye units should use this event to innovate, not just survive but to also evolve for a sustainable future. In this article, we discuss the inadequacies of existing service rationing options to tackle the COVID-19 cataract backlog. This includes limiting rationing based on visual acuity, limiting surgery to first or only seeing eyes, and postponing clinic and surgical dates according to referral dates. We propose units use the lockdown time to reset and develop a comprehensive patient-centred care pathway using principles of value-based healthcare: the cataract integrated practice units. Developing an agile surgical database that incorporates all aspects of patient need from education to follow-up in their individual cataract journey will allow units to react and plan quickly in the early phase of recovery and beyond. We also discuss the considerations units should bear in mind on telemedicine, modifications for face-to-face clinics, theatre organisation and options of expanding cataract throughput capacity. The pause in elective surgery due to the pandemic may have provided cataract services a rare opportunity to reset and transform cataract service pathways for the digital era.

\section{INTRODUCTION}

The WHO declared COVID-19 a Public Health Emergency Of International Concern on 30 January 2020. ${ }^{1}$ NHS England and NHS Improvement (NHSEI) announced COVID-19 a Level 4 National Incident on 17 March 2020 and instructed NHS trusts to reduce and eventually suspend elective services to maximise capacity for the potential surge in intensive care demand. ${ }^{2}$ The Royal College of Ophthalmologists (RCOphth) on 28 March 2020 recommended eye units to suspend all elective eye operations and postpone non-urgent outpatient clinics. ${ }^{3}$ The implementation of these measures has resulted in severe disruption to cataract services.

WHO estimates visually impairing cataracts are the second largest cause of treatable visual impairment globally, affecting 60 million worldwide. ${ }^{4}$ In the UK, 2.2 million people are living with sight loss, and $19 \%$ of these are due to cataracts. ${ }^{5}$ The estimated cataract operations for 2020 were between 8452 and 9115 per week pre-COVID-19. ${ }^{6-9}$ NHSEI has recently encouraged trusts to tentatively plan for elective service restart. ${ }^{10}$ After a 14 -week hiatus, if we optimistically assume full services can resume safely by 1 July 2020, providers will still face a $50 \%$ workload increase per week if the aim is to clear all backlogs by the end of 2020 .

In this article, we discuss the dilemmas and opportunities the pandemic has presented to cataract services within the NHS.

\section{CURRENT SERVICE RATIONING OPTIONS}

There are several options currently discussed for cataract service recovery. Although each can provide a seemingly simple logistical solution, there is no one silver bullet.

\section{Option 1: rationing based on visual acuity}

Commissioners often use visual acuity (VA) of 6/12 as a threshold for cataract surgery rationing based on the WHO definition of visual impairment. ${ }^{11}$ The National Ophthalmology Database audit Year 4 report found $34.6 \%$ of the patients with cataract have VAs 6 / 12 or better. ${ }^{12}$ If we exclude these patients from the predicted pre-COVID-19 backlog, the $50 \%$ predicted recovery workload increase can be reduced to a $2 \%$ decrease (8291-8942 cases per week). While this approach seems to offer a straightforward solution that prioritises severe cataracts, it is neither patientcentred nor advocated by the National Institute for Health and Care Excellence (NICE) guidelines. ${ }^{13}$

VA alone is an incomplete measure of patient disability, as the full impact of a cataract on a patient's quality of life depends on individuals' overall visual requirements in different environmental or task settings. Therefore, to disqualify a patient with better than $6 / 12$ vision without considering their individual circumstances would not maximise the intended cost-effectiveness of surgery.

Cataract surgery is the most commonly performed operation and the most cost-effective surgical intervention in improving quality of life, with an average expected welfare gain of $£ 1110$ in the year after, for a surgery cost of $£ 672 .^{14} 15$ PostCOVID19, services should refrain from using a VA threshold, instead redesign their currently existing patient surgery decision-making aides (PSDMA) to ensure the right patient is operated at the right time.

Getting It Right the First Time national report for Ophthalmology found units with well-established PSDMA tools can achieve an 80-85\% cataract referral-to-surgery conversion rate. ${ }^{16}$ The post-COVID PSDMA tool should combine existing NICE recommendations with recently published RCOphth and United Kingdom and Ireland Society of Cataract and Refractive Surgeons (UKISCRS) post-COVID guidelines to aid waiting list validation and prioritisation in the recovery phase, ${ }^{17}$ and where possible use validated tools to glean quantifiable data (table 1). 
Table 1 Considerations for designing post-COVID PSDMA tools

\begin{tabular}{|c|c|}
\hline Existing criteria as per NICE & Post-COVID additional considerations \\
\hline The effect of the cataract on the vision and quality of life & $\begin{array}{l}\text { To use validated patient-reported measures to quantify the effect (eg, CAT-PROM5 }{ }^{18} \text { or Catquest- } \\
9 \mathrm{SF}^{19} \text { ) }\end{array}$ \\
\hline Cataract affecting one or both eyes & $\begin{array}{l}\text { To check for degrees of current or potential postoperative anisometropia, for example, preoperative } \\
\text { refraction } \\
\text { To measure binocular vision, reading vision } \\
\text { To measure functional visual acuity (eg, Real-Life Vision Test) }\end{array}$ \\
\hline $\begin{array}{l}\text { Explanation and details of cataract surgery procedure including risks and } \\
\text { benefits }\end{array}$ & To check co-existing ocular comorbidities that prompt or deter surgery. See table 2. \\
\hline Exploration of the impact on quality of life without cataract surgery & $\begin{array}{l}\text { To know driving and working status, including types of work. } \\
\text { To complete fall risk scores (if applicable). }\end{array}$ \\
\hline Desire to have cataract surgery & To include actual and patient perceived COVID-19 exposure risk. ${ }^{17}$ \\
\hline
\end{tabular}

PSDMA, patient surgery decision-making aides; NICE, National Institute for Health and Care Excellence.

Table 2 Ocular comorbidities that may affect decision on cataract surgery

\begin{tabular}{ll}
\hline Disease prompting early surgery & Diseases leading to guarded/worse outcome \\
\hline Phacomorphic glaucoma & End-stage glaucoma \\
\hline Funduscopy unable to be performed due to dense cataract & Advanced optic neuropathy/pale disc \\
\hline Diabetic retinopathy screening & Advanced age-related macular degenerationwith geographic atrophy \\
Only eye with advanced cataract affecting quality of life & Pre-existing macular scar involving the fovea \\
Severe anisometropia & Pre-existing retinal disease causing scarring or loss of function \\
\hline Hyper-mature cataract & \\
\hline
\end{tabular}

A digital-enabled tool should enable instant user feedback and education to refine and sustain its implementation.

\section{Option 2: limit surgery to first or only seeing eyes}

This maximises the number of patients served by limited theatre resources. However, it assumes improvement of the worse eye provides betterment in overall quality of outcome for all patients at a lower cost, which is not true.

Cost-utility analyses of second-eye surgery have shown that it represents good value. Cataract surgery also has indirect social and health-economic advantages in improving wellbeing, reducing isolation and premature need for care and road traffic accidents. ${ }^{6} 20$ Considering the mean age of patients undergoing cataract surgery in the NHS is 76 , it is critical that these patients have early access to second-eye surgery. Research shows patients who have access to secondeye surgery may experience fewer falls (18\% vs $25 \%)$ and fewer fractures (3\% vs $12 \%){ }^{21} \mathrm{New}$ evidence also suggests that rates of falling may increase after first-eye surgery, which is then offset by second-eye surgery. ${ }^{21} 22$ Increased risk of falls may cause significant injury that requires inpatient care in the elderly, which in the immediate post-COVID phase could be hazardous. Moreover, leaving a patient with significant anisometropia may negatively impact their ability to drive and work, and leave them functionally worse after surgery.

Therefore, other measures of visual function such as binocular vision and Real-Life Vision Test should be considered when deciding first- and/or second-eye surgery. ${ }^{23} 24$ These may also help to decide suitability for immediate sequential bilateral cataract surgery (table 1).

\section{Option 3: postponing clinic and surgical dates according to RTT} For patients already listed for surgery and those awaiting first appointment for cataract assessment, postponing them according to their current position on the lists may appear as the simplest administrative solution. However, presently the order of cataract appointments and waiting list is organised as per the referral-totreatment (RTT) requirements. This is an NHS pledge to patients to complete their treatment in hospital within 18 weeks of the referral being made from their primary care clinician. Thus, the lists are organised by referral dates rather than prioritising according to clinical, social and economic parameters of individual patients.

For the post-COVID-19 world, it is vital that lists take into account which patient is able to wait; who has conditions that will worsen if delayed; whose eye, sight or general health (eg, fall risk) will be irretrievably harmed; and whose surgical risk may increase due to increased surgical difficulty from a maturing cataract. The latest guidelines published by RCOphth/UKISCRS also recommend reassessing and prioritising surgery based on clinical need. ${ }^{25}$ New Zealand already applies these principles in their Clinical Priority Assessment Criteria; its cataract module includes detailed scoring for driving and independent living and risk of mature cataracts; however, it does not contain assessment on future risk of surgery as a criterion. ${ }^{26}{ }^{27}$ Units should invest to develop digitally enabled prioritising software locally using the aforementioned criteria.

\section{EFFECT OF COVID-19 EXPOSURE RISK AND ISOLATION REQUIREMENTS}

There are two key elements to consider which influence patient attendance: (1) the patient's perception of COVID-19 exposure risk and (2) the imposed restrictions from Public Health England (PHE) for vulnerable citizens.

The attendance in emergency departments and general practitioner surgeries has seen a dramatic decline in recent months. ${ }^{28}$ Anecdotal reports from clinicians suggest that patients are reluctant to attend hospital despite having serious conditions; this changed willingness to access healthcare will need to be considered and alleviated. Aier Eye Hospital in China reopened elective services on 8 April 2020 and used online videos to educate 
patients about the safety, and the importance of attending clinical and surgical appointments. ${ }^{29}$

Patient attendance will be subject to changes in PHE guidance on social distancing, isolation and shielding. Of the patients attending cataract clinics, $78 \%$ are 70 years or older, $11 \%$ have diabetes, $57 \%$ have one or more systemic comorbidities ${ }^{30}$; as per PHE, the presence of these factors classifies these patients as 'vulnerable' or 'extremely vulnerable' and recommends such individuals to remain in self-isolation and refrain from attending elective or routine appointments until at least 30 June $2020 .^{31}$ This means that in the early recovery phase, less than $22 \%$ of the patients will be able to attend face-to-face cataract assessment clinics and surgery; not including individuals who may need to self isolate at short notice due to self or household developing COVID-19 symptoms.

The Government's Scientific Advisory Group for Emergencies (SAGE) currently reviews social distancing measures every 21 days; thus, official guidance remains volatile subject to factors such as testing, vaccines, second wave of COVID-19 infection in autumn or seasonal recurrences. Hence, units will need a service that is agile to change.

\section{REDESIGNING FOR THE FUTURE}

\section{Patient streams: the integrated practice units}

Various risk stratification methods are in use in the UK. Examples include the Cat-12 tool, the cataract complexity score ${ }^{6} 18$ and the built-in posterior capsule rupture (PCR) complication risk score in the Medisoft system. ${ }^{32}$ These methods correlate PCR risk with patient factors, surgical factors and surgeon experience. For example, a trainee will have a higher predicted complication rate for a white cataract compared to a consultant. These risk assessment tools were originally designed for balancing service provision, training and allocating the cases to the correct level of surgeon for patient safety. NICE guidelines also recommend its use for predicting cataract surgical risk from delay. ${ }^{13}$ However, it is commonly used as a tool for designing high volume lists. These systems can make unmeasured assumptions and equate low surgical risk to a shorter theatre throughput duration for a low cost, which can be misleading in some cases; for example, a claustrophobic patient with low surgical risk cataract may take a longer time than a patient with white cataract operated by a senior surgeon, and end up being more expensive due to sedation cost.
Instead, cataract services should be designed as integrated practice units (IPU). This is the core of value-based healthcare where complete care pathways would include education, engagement, treatment and follow-up all the way to patient-reported outcome measures. ${ }^{33}{ }^{34}$ Cases can be first defined by patient- and surgery-specific characteristics (table 3), then organised into complex or routine IPUs (figure 1)

All patients present and future can be categorised now during the suspension of elective work using telemedicine, incorporating all aspects of the care cycle. The agile surgical database developed should produce specific patient lists, capable of adapting to lastminute requirement changes. Using improvement tools provided by NHS Improvement, the new system should be modified and adjusted according to measured outcomes, to ensure quality and sustainability for the future. ${ }^{36}$

\section{Telemedicine for virtual cataract service}

COVID-19 pandemic has seen an exponential growth in the utilisation of telemedicine to provide service, for example, telephone follow-ups and the video consultation platform NHS AttendAnywhere. ${ }^{37}$

We propose a 'Virtual-Plus' model for the future cataract service, akin to the well-established virtual glaucoma clinic. ${ }^{38} 39$ A PSDMA enabled e-referral from an optometrist to a cataract service marks the start. Accepted patients are sent tailored cataract-related e-resources prior to their first video consultation with clinicians to clarify the diagnosis and the surgery. The patientspecific information collected throughout can be fed into a patient streaming database. Patients listed for surgery then subsequently progress into a face-to-face diagnostic clinic where patient's physical parameters such as intraocular pressures, biometry, and anterior and posterior segment photographs will be performed by technicians in hospital or by community optometrists. ${ }^{40}$ Surgeons can then remotely review the acquired diagnostic data and finalise surgical plans with the patient with a second video consultation discussing refractive outcome and complete e-consenting, followed by nurse-led pre-assessment in the same session. Remote pre-assessment has been shown to be safe and cost-effective. ${ }^{41}$ Subsequent postoperative reviews with community optometrists or by allied health professionals can bring care to the patient, and both have demonstrated safety and efficiency. ${ }^{6}{ }^{42}$

Table 3 Definitions of patient and surgery specific characteristics

\begin{tabular}{|c|c|c|}
\hline & Routine cataract & Complex cataract \\
\hline \multirow[t]{4}{*}{ Surgery related } & $\begin{array}{l}\text { Suitable for any level of surgeons } \\
\text { Consultant supervision not required for senior trainee surgeons } \\
\text { PCR risk score low }\end{array}$ & $\begin{array}{l}\text { Consultant only or } \\
\text { In theatre supervision required } \\
\text { PCR risk score high }\end{array}$ \\
\hline & Surgical time $<20 \mathrm{~min}$ & Additional time needed \\
\hline & & Additional equipment required \\
\hline & Routine patient & Complex patient \\
\hline \multirow[t]{4}{*}{ Patient related } & No significant medical problems & 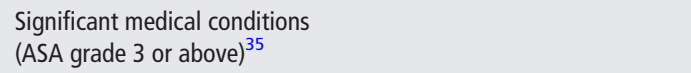 \\
\hline & $\begin{array}{l}\text { No need for anaesthetic cover in the theatre } \\
\text { (ASA grade } 1 \text { or } 2)^{35}\end{array}$ & $\begin{array}{l}\text { Anaesthetic cover required due to } \\
\text { 1. Intravenous sedation or GA required for safe surgery, for example, } \\
\text { positioning, patient anxiety or learning disability. } \\
\text { 2. Medical conditions requiring intraoperative monitoring by an } \\
\text { anaesthetist (ASA grade } 3 \text { or above), for example, pacemaker. }\end{array}$ \\
\hline & Independently mobile & Mobility or positioning issues. \\
\hline & Overall theatre time $<30 \mathrm{~min}$ & Overall theatre time $>30 \mathrm{~min}$. \\
\hline
\end{tabular}

ASA, American Society of Anesthesiologists; GA, geographic atrophy; PCR, posterior capsule rupture. 


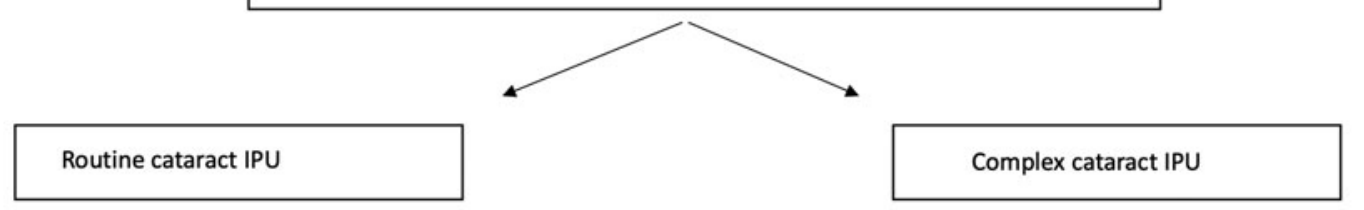

- Patients defined as both routine cataract and routine patient.
- Suitable for high volume weekend / evening / fellow
independent lists.
- Suitable for parallel lists with consultants operating on
- Suitable for topical or local anaesthetic alone.
- Suitable for community or non-Ophthalmologist pre-/post op
follow-up ( face to face or virtually).

Figure 1 Complex and routine IPUs designed around the characteristics of patients and their cataracts.

We anticipate this model may not suit all due factors such as lack of digital capability within the unit or the users, unsuitable patients or complex cataracts, for example, dense cataracts or learning disability; patient choice or clinician preference. Ophthalmic units should endeavour to use NHS digital transformation resources to enhance telemedicine development, update electronic medical records and update workforce digital capabilities to enable a stepwise implementation. Adapting the VirtualPlus model will provide a COVID-safe approach and release clinic capacity for unavoidable face-to-face appointments.

\section{Modification to face-to-face encounters}

The current practice of pre-entry screening of temperature, symptoms and contact checks may continue. ${ }^{17}$ As SAGE continues to review evidence and announce new guidelines, units must remain versatile to adapt to different protocols quickly. Contact tracing apps, ${ }^{43}$ vaccinations, swab-test-and trace, future lockdowns and personal protective equipment (PPE) guideline modification will continue to influence practice. Units can facilitate correct practice by addressing infection control, environmental and administrative modifications. These include, but are not limited to, floor markings to ensure correct social distancing is followed, hand hygiene facilities and implementing slit-lamp breath guards. But more importantly, units should adapt educational resources to ensure that both patients and members of staff are constantly updated and reminded of the correct practices of safety measures (eg, short videos and posts on social media, posters in clinical areas and text alerts).

The conventional admission process for surgery day where all patients arrive at the same time, the surgeon performing a 30-90 min preoperative ward round, the patient then waiting between $30 \mathrm{~min}$ and 5 hours for their turn in surgery depending on the order of the list and patient load, followed by $30-45 \mathrm{~min}$ discharge process, should cease. As this causes 1 hour surgical theatre time loss at the beginning of the list, and up to 5 hours of waiting time for the patients, instead, patients should be staggered by time, and according to the available space capacity respecting social distancing measures. Patients can be given dilating drops to self-prepare for surgery, further reducing admission time. These measures will enable units to use staff time efficiently, reduce patient journey time in hospital, respect social distancing, deploy infection control measures and conserve PPE supply.

Facility and pathway assessment, process map modelling and mock clinic/theatre list simulations should be conducted and reviewed according to the NHS quality improvement Plan-DoStudy-Act cycle to identify potential problems, for example, local outbreak of COVID-19. This will ensure adequate time, facility and contingency measures are in place and rehearsed before reopening any face-to-face services. ${ }^{44}$

\section{Theatre organisation}

Operation lists will need to balance efficiency and safety for both patient and staff for the recovery phase and for future. In general, theatre lists can also be segregated according to complex and routine IPUs then modified according to the phase of recovery required. See table 4.

RCOphth/UKISCRS recommend that surgeons and theatre staff use filtering facepiece respirators and eye protection where possible when performing cataract surgery in compliance with the PHE guidance for aerosol-generating procedures. ${ }^{17}$ Due to existing uncertainties during various recovery phases, it may be safest to start with a reduced routine list staffed by senior surgeons to maximise theatre operation time and mitigate exposure. ${ }^{17}$ Local and PHE infection control measures for elective surgery should be incorporated, simulated and tested to ensure patients and staff safety.

\section{Theatre availability}

Cataract surgery may face competition for precious theatre resources with other ophthalmology subspecialities or other 
Table 4 Theatre list design for routine and complex IPUs

\begin{tabular}{|c|c|c|}
\hline & Routine list & Complex list \\
\hline IPU group & Routine IPU patients & Complex IPU patients \\
\hline Patients per list & Up to 8-10 per 4-hour session & Up to 6 per 4-hour session \\
\hline Operating staff & $\begin{array}{l}\text { Consultant/senior trainee } \\
\text { Operating department practitioner } \\
\pm \text { junior trainee surgeon able to complete surgery } \\
\text { within } 20 \text { min }\end{array}$ & $\begin{array}{l}\text { Consultant surgeon } \\
\text { Anaesthetist } \\
\pm \text { any level trainee surgeon }\end{array}$ \\
\hline Time & $30 \mathrm{~min}$ & Extra time required $>30 \mathrm{~min}$ \\
\hline Early recovery phase & $\begin{array}{l}\text { Reduced to } 4-5 \text { patients to start } \\
\text { Double tandem theatre teams }\end{array}$ & Not performed \\
\hline Full service phase & $\begin{array}{l}\text { Work towards high volume lists } \\
\text { Build initiative lists to clear backlog }\end{array}$ & Reduced list initially and slow recovery \\
\hline
\end{tabular}

IPU, integrated practice units.

surgical specialities for procedures deemed more urgent. It may be hard to argue cataract surgery against cancer surgery. Several methods of enhancing throughput in the cataract service already exist. Post-COVID-19 demand may propel these into wider implementation.

\section{High-throughput cataract surgery}

Sunderland eye infirmary has been nationally recognised for best practice for this well-established service delivery model that yields 170-180 cataract operations weekly. ${ }^{45}$ Not all units will have the facilities or manpower to implement the same practice. One option can be to collaborate with adjacent units and create regional high throughput centres for the routine IPU patients. Beyond COVID-19, these facilities may evolve into high-volume surgical centres of excellence as the NHS commissioning structure moves towards the development of integrated care systems (ICS) covering larger geographic areas. ${ }^{46}$

\section{Immediate sequential bilateral cataract surgery}

Immediate sequential bilateral cataract surgery (ISBCS) has been shown to be as safe and effective to conventional delayed sequential bilateral cataract surgery. ${ }^{47}$ Its advantages include decreased wait time for surgery, reduced clinical visits, convenience for patients and overall saving for healthcare systems. ${ }^{48}$ Currently, ISBCS in the UK is offered to limited patients who require general anaesthesia for social reasons, for example, patients with learning difficulty. ${ }^{49}$ Post-COVID, the real benefit of bilateral surgery should be applied to carefully selected, counselled and consented patients. ${ }^{50}$

\section{Cataract surgery by appointment}

This is a model where patients self-prepare for surgery, arrive and discharge directly from the operating theatre. An efficient process can see the patient spending as little as $20 \mathrm{~min}$ in the eye unit. However, additional care must be borne when selecting patients for this model to ensure that they are able to understand instructions and provide safe self-care preoperatively and postoperatively. ${ }^{51}$

\section{Constraints against change}

It is important to remember tariff and staff are usually the main constraints against service remodelling. Take ISBCS for example, it may demonstrate more efficiency, but the second-eye surgery does not automatically equate to increased payment. ${ }^{48}$ Trusts all moved onto blocked contracts from 1 April to 31 July 2020, suspending payment-by-result architecture. ${ }^{2}$ This may or may not continue post-COVID recovery to every trust. Change to service models is inevitable; thus, trusts need to engage and collaborate with commissioners early so that innovative pathways are supported to ensure sustainability.

COVID-19 has demonstrated incredible NHS staff mobilisation and adaptation capabilities when the goal is clear and well communicated: to increase capacity, to save lives. Therefore, units should extend from this experience to build a collaborative working culture that promotes teamwork and user-centric service designs.

\section{Training}

Suspension of elective surgery will have hampered cataract surgery training for at least 14 weeks. The recovery plan to clear surgical backlog and mitigate exposure risk will certainly further delay the training of junior non-independent surgeons. Trainees should therefore have access to EyeSi simulator during this period to maintain and practice their skills, enabling them to maximise their training opportunity in theatre when available. ${ }^{52}$ Units with clearly categorised patients within an agile surgical database will be able to design intensive cataract training lists, which has demonstrated to produce safer surgeons. ${ }^{53}$

\section{CONCLUSION}

The COVID-19 pandemic has propelled the NHS into uncharted service improvement territory at lightning speed. This is a rare opportunity for us to reset and transform cataract service pathways for the digital era. Combining an agile patient-centred streaming system capable of quickly adapting to the ever-changing environment with wider applications of telemedicine and novel models of care will ensure the cataract service not just survives COVID-19 but evolves into a robust practice model for the future.

It is now the dawn of the next-generation cataract service.

Contributors P-FL and $\mathrm{CL}$ jointly devised the project, the main conceptual ideas and proof outline. P-FL did the writing of the manuscript with support from $\mathrm{HN}, \mathrm{ME}$ and $\mathrm{CL}$. ME also contributed to the design and contents of the tables and figures. All authors discussed the content and commented on the manuscript.

Funding This research received no specific grant from any funding agency in the public, commercial or not-for-profit sectors.

Competing interests None declared.

Provenance and peer review Not commissioned; externally peer reviewed.

\section{ORCID iD}

Pei-Fen Lin http://orcid.org/0000-0001-7661-7611

\section{REFERENCES}

1 WHO. Statement on the second meeting of the International Health Regulations (2005) Emergency Committee regarding the outbreak of novel coronavirus (2019-Nov). World Health Organization. 2020. Available https://www.who.int/news-room/detail/30-012020-statement-on-the-second-meeting-of-the-international-health-regulations -(2005)-emergency-committee-regarding-the-outbreak-of-novel-coronavirus-(2019ncov) (accessed 21 Apr 2020). 
2 Stevens S, Pritchard A. Next steps on NHS response to COVID-19. NHS England and NHS Improvement. 2020. Available https://www.england.nhs.uk/coronavirus/wpcontent/uploads/sites/52/2020/03/urgent-next-steps-on-nhs-response-to-covid-19letter-simon-stevens.pdf (accessed 21 Apr 2020).

3 RCOphth: management of ophthalmology services during the Covid pandemic. Royal College of Ophthalmologists. 2020. Available https://www.rcophth.ac.uk/wp-content /uploads/2020/03/RCOphth-Management-of-Ophthalmology-Services-during-theCovid-pandemic-280320.pdf (accessed 28 Apr 2020).

4 Vision impairment and blindness. World Health Organisation. 2019. Available https:// www.who.int/news-room/fact-sheets/detail/blindness-and-visual-impairment (accessed 21 Apr 2020).

5 The state of the nation eye health 2016. RNIB. 2016. Available https://www.rnib.org. uk/sites/default/files/RNIB\%20State\%20of\%20the\%20Nation\%20Report\% 202016\%20pdf.pdf (accessed 21 Apr 2020).

6 Buchan J. The way forward: options to help meet demand for the current and future care of patients with eye disease. Cataract. The Royal College of Ophthalmologists. 2017. Available https://www.rcophth.ac.uk/wp-content/uploads/2015/10/RCOphthThe-Way-Forward-Cataract-300117.pdf (accessed 24 Apr 2020).

7 National Ophthalmology Database. National Ophthalmology Database audit key findings summary 2017-2018. Royal College of Ophthalmologists. 2019. Available https://www.nodaudit.org.uk/u/docs/20/hfsjzvezyj/Key\%20Findings\%20Summary\% 202019.pdf (accessed 11 Jun 2020).

8 Finished admission episodes waiting times for hip replacements, cataract surgery and hysterectomy - NHS digital. NHS Digital. Available https://digital.nhs.uk/data-andinformation/find-data-and-publications/supplementary-information/2018supplementary-information-files/finished-admission-epiodes-waiting-times-for-hipreplacements-cataract-surgery-and-hysterectomy (accessed 11 Jun 2020).

9 Minassian D, Reidy A. Future sight loss UK (2): an epidemiological and economic model for sight loss in the decade 2010-2020. RNIB. 2009.Available https://www.rnib.org. uk/sites/default/files/FSUK_Summary_2.pdf (accessed 22 Apr 2020).

10 Stevens S, Pritchard A. Letter to chief execs: for action - second phase of NHS response to COVID 19. NHS England. April 29, 2020. Available https://www.england.nhs.uk/ coronavirus/wp-content/uploads/sites/52/2020/04/second-phase-of-nhs-response-tocovid-19-letter-to-chief-execs-29-april-2020.pdf (accessed 11 Jun 2020).

11 Vision impairment and blindness. Available https://www.who.int/en/news-room/factsheets/detail/blindness-and-visual-impairment (accessed 14 Jun 2020).

12 Donachie P, Sparrow J. National Ophthalmology Database audit: year 4 annual reportthe third prospective report of the National Ophthalmology Database audit. NHS funded cataract surgery: 01 september 2017 to 31 August 2018. Full comprehensive report 2019. RCOphth. 2019. Available https://www.nodaudit.org.uk/u/docs/20/twkmamtbwf/ NOD\%20Full\%20Comprehensive\%20Report\%202019.pdf (accessed 11 Jun 2020).

13 Recommendations | cataracts in adults: management | guidance | NICE. Available https://www.nice.org.uk/guidance/ng77/chapter/Recommendations\#surgical-timingand-technique (accessed 9 May 2020).

14 Weale M. A cost-benefit analysis of cataract surgery based on the English Longitudinal Survey of Ageing. J Health Econ 2011;30:730-9.

15 The Royal College of Ophthalmologists. RCOphth follow-up survey finds continued cataract rationing imposed by CCGs despite NICE guidance - The Royal College of Ophthalmologists. The Royal College of Ophthalmologists. 2019. Available https:// www.rcophth.ac.uk/2019/04/rcophth-follow-up-survey-finds-continued-cataractrationing-imposed-by-ccgs-despite-nice-guidance/ (accessed 11 Jun 2020).

16 MacEwan C, Davis A, Chang L. Getting It Right the First Time: ophthalmology GIRFT programme national specialty report. Getting It Right the First Time. 2019. Available https://gettingitrightfirsttime.co.uk/wp-content/uploads/2019/12/ OphthalmologyReportGIRFT19S.pdf (accessed 11 Jun 2020).

17 RCOphth COVID-19 Review team and UKISCRS. Cataract surgery during COVID-19 pandemic. Royal College of Ophthalmologists. 2020. Available https://www.rcophth. ac.uk/wp-content/uploads/2020/04/RCOphth-UKISCRS-COVID-cataract-surgeryguidance-FINAL-170420.pdf (accessed 28 Apr 2020).

18 Sparrow JM, Grzeda MT, Frost NA, et al. Cat-PROM5: a brief psychometrically robust self-report questionnaire instrument for cataract surgery. Eye 2018;32:796-805.

19 International Consortium for Health Outcome Measurement. ICHOM data collection reference guide: cataracts. ICHOM. 2017.Available https://ichom.org/files/medicalconditions/cataracts/cataracts-reference-guide.pdf (accessed 6 May 2020).

20 Meuleners LB, Brameld K, Fraser ML, et al. The impact of first- and second-eye cataract surgery on motor vehicle crashes and associated costs. Age Ageing 2019;48:128-33.

21 Foss AJE, Harwood RH, Osborn F, et al. Falls and health status in elderly women following second eye cataract surgery: a randomised controlled trial. Age Ageing 2006:35:66-71.

22 Harwood RH, Foss AJE. Second-eye cataract surgery: valuable investment or unaffordable luxury? Age Ageing 2014;43:310-2.

$23 \mathrm{Ni} \mathrm{W}, \mathrm{Li}$ X, Ao M, et al. Using the real-life vision test to assess the functional vision of age-related cataract patients. Eye 2012;26:1402-11.

24 Comas M, Castells X, Acosta ER, et al. Impact of differences between eyes on binocular measures of vision in patients with cataracts. Eye 2007;21:702-7.

25 RCOphth COVID-19 REVIEW TEAM and UKISCRS. Cataract surgery guidelines for post COVID-19 pandemic: recommendations. 2020. Available https://www.rcophth.ac.uk/
wp-content/uploads/2020/05/RCOphth-UKISCRS-COVID-cataract-surgery-restoringservices-070520.pdf (accessed 11 Jun 2020).

26 Feek CM. Rationing healthcare in New Zealand: the use of clinical guidelines. Med J Aust 2000;173:423-6.

27 National clinical priority assessment criteria: ophthalmology. HFA. 2001. Available http://www.spitalmures.ro/_files/protocoale_terapeutice/oftalmologie/ophthalmol ogy-cpac.pdf (accessed 6 May 2020).

28 West D. Some hospitals left 'quiet' as covid-19 sparks huge fall in attendances. Health Service Journal. Available https://www.hsj.co.uk/acute-care/some-hospitals-left-quietas-covid-19-sparks-huge-fall-in-attendances/7027244. article (accessed 30 Apr 2020)

29 Chien C. World Association of Eye Hospitals webinar keynote speech for Aier Eye Hospital Group 'clinic and surgery rescaling strategies and best practices'. 2020.

30 Desai P, Reidy A, Minassian DC. Profile of patients presenting for cataract surgery in the UK: national data collection. Br J Ophthalmol 1999;83:893-6.

31 Public Health England. Guidance on shielding and protecting people who are clinically extremely vulnerable from COVID-19. GOV.UK. 2020. Available https://www.gov.uk/ government/publications/guidance-on-shielding-and-protecting-extremely-vulnerable -persons-from-covid-19/guidance-on-shielding-and-protecting-extremely-vulnerablepersons-from-covid-19 (accessed 24 Apr 2020).

32 Narendran N, Jaycock P, Johnston RL, et al. The cataract national dataset electronic multicentre audit of 55,567 operations: risk stratification for posterior capsule rupture and vitreous loss. Eye 2009;23:31-7.

33 Porter ME. What is value in health care? N Engl J Med 2010;363:2477-81.

34 Porter ME, Lee TH. Why strategy matters now. N Engl J Med 2015;372:1681-4.

35 ASA physical status classification system. ASA. Available https://www.asahq.org/stan dards-and-guidelines/asa-physical-status-classification-system (accessed 6 May 2020).

36 Quality, service improvement and redesign (QSIR) tools | NHS Improvement. Available https://improvement.nhs.uk/resources/quality-service-improvement-and-redesign-qsir -tools/ (accessed 9 May 2020).

37 Sim D, Thomas P, Canning C. Tackling COVID-19 with telemedicine. The Ophthalmologist. 2020. Available https://theophthalmologist.com/subspecialties/tack ling-covid-19-with-telemedicine (accessed 30 Apr 2020).

38 Royal College of Ophthalmologists. Ophthalmic services guidance standards for virtual clinics in glaucoma care in the NHS hospital eye service. RCOphth. 2016. Available https://www.rcophth.ac.uk/wp-content/uploads/2017/03/Virtual-Glaucoma-Clinics. pdf (accessed 14 Jun 2020).

39 Nelson C, Hansemann B, Shtein R, et al. World association of eye hospitals Webinar: COVID-19 - PPE \& surgical throughput - how to balance both? Keynote lecture from Kellogg Eye Center, USA. Available https://knowledgehub.waeh.org/coronacommunity-of-practice (accessed 28 May 2020).

40 RCOphth. Standards for virtual clinics in glaucoma care in the NHS hospital eye service. The Royal College of Ophthalmologists. 2016.Available https://www.rcophth.ac.uk/wpcontent/uploads/2017/03/Virtual-Glaucoma-Clinics.pdf (accessed 9 May 2020).

41 Keay LE. Routine preoperative medical testing for cataract surgery. PubMed - NCBI. Available https://www.ncbi.nlm.nih.gov/pubmed/9370681 (accessed 1 May 2020).

42 Hoffman JJSL, Pelosini L. Telephone follow-up for cataract surgery: feasibility and patient satisfaction study. Int J Health Care Qual Assur 2016;29:407-16.

43 Digital contact tracing: protecting the NHS and saving lives. Available https://www. nhsx.nhs.uk/blogs/digital-contact-tracing-protecting-nhs-and-saving-lives/ (accessed 1 May 2020).

44 Plan, Do, Study, Act (PDSA) cycles and the model for improvement | NHSImprovement. Available https://improvement.nhs.uk/resources/pdsa-cycles/ (accessed 9 May 2020).

45 Hingorani M Sunderland eye infirmary: a case study of high throughput cataract surgery. UK Ophthalmological Alliance. 2018. Available https://uk-oa.co.uk/wp-content/uploads/ 2018/07/UKOA_Sunderland_Case_Study_June_2018.pdf (accessed 9 May 2020).

46 NHSEl. Refreshing NHS plans for 2018/19 published by NHS England and NHS Improvement. 2018. Available https://www.england.nhs.uk/wp-content/uploads/ 2018/02/planning-guidance-18-19.pdf (accessed 12 Jun 2020).

47 Herrinton LJ, Liu L, Alexeeff S, et al. Immediate sequential vs. delayed sequential bilateral cataract surgery: retrospective comparison of postoperative visual outcomes. Ophthalmology 2017;124:1126-35.

48 Singh R, Dohlman TH, Sun G. Immediately sequential bilateral cataract surgery: advantages and disadvantages. Curr Opin Ophthalmol 2017;28:81-6.

49 Buchan JC, Donachie PHJ, Cassels-Brown A, et al. The Royal College of Ophthalmologists National Ophthalmology Database study of cataract surgery: report 7, immediate sequential bilateral cataract surgery in the UK: current practice and patient selection. Eye 2020.

50 Smith GT, Liu CS. Is it time for a new attitude to 'simultaneous' bilateral cataract surgery? Br J Ophthalmol 2001;85:1489-96.

51 Mavrikakis I, Georgiou T, Paul B, et al. Cataract surgery by appointment: a pilot study. BMC Ophthalmol 2006;6.

52 Ferris JD, Donachie PH, Johnston RL, et al. Royal College of Ophthalmologists' National Ophthalmology Database study of cataract surgery: report 6 . The impact of EyeSi virtual reality training on complications rates of cataract surgery performed by first and second year trainees. Br J Ophthalmol 2020;104:324-9.

53 Baxter JM, Lee R, Sharp JAH, et al. Intensive cataract trining: a novel approach. Eye 2013:27:742-6 